\title{
Correspondence
}

\section{Relieving anxiety by entering the oper- ating room on foot}

To the Editor:

We hypothesized that entering the operating room (OR) lying on a gurney increased anxiety, and investigated the effects of entering on foot compared to gurney transport with premedication.

From October 1998 through September 2000, we evaluated the preoperative anxiety of patients aged 15 to $80 \mathrm{yr}$ old with clear consciousness who received elective surgery under general anesthesia at Suwa Red Cross Hospital. With the approval of hospital Ethics Committee and informed consent, 672 patients were premedicated with hydroxyzine $(50-100 \mathrm{mg}$ ) and atropine sulfate $(0.4-0.5 \mathrm{mg})$ intramuscularly and transferred to the OR on a gurney 30 min later (gurney group); while 686 patients entered the OR on foot without premedication (on-foot group). Two nurses, who greeted the patient at the OR entrance, assessed the patient's psychological status based on the patient's replies and physical signs of facial expression, manner of speech or spontaneous movement of limbs, and classified it into one of four categories: oversedated, sedated, calm or mildly anxious, and highly anxious. Gurney group and on-foot group were similar in age $(55.3 \pm$ 15.5 and $54.3 \pm 16.9$ yr old), gender (51.0 and $50.9 \%$ female), and surgical field distribution.

Our results show a significantly greater number of highly anxious patients, more sedated patients notwithstanding, among the gurney group compared to the on-foot group (Table). ${ }^{4}$

There are possible explanations for the result. Walking and the accompanying chatter may have relaxed patients, while lying on a gurney accelerated preoperative anxiety. Preoperative transport on a gurney may be stressful to patients because it is difficult to see and talk to other people looking down at them. In our experience, the apparent underestimation of the effect of premedication may be due to evaluation of patients upon entrance in the OR since, in many previous reports, this evaluation was made on the ward and the stress of transport was eliminated. Moreover, some patients in the gurney group expressed anxiety despite being in a drowsy state with their eyes closed. While hydroxyzine is a relatively mild premedicant, ${ }^{1}$ more potent sedatives have side
TABLE Anxiety level of preoperative patients

\begin{tabular}{llll}
\hline Anxiety level & $\begin{array}{l}\text { Gurney group } \\
n=672\end{array}$ & $\begin{array}{l}\text { On-foot group } \\
n=686\end{array}$ & P value \\
\hline Oversedated & 0 & 0 & \\
& $(\%)$ & $(0)$ & $(0)$ \\
Sedated & 86 & 4 & $<0.001$ \\
& $(\%)$ & $(12.8)$ & $(0.5)$ \\
Calm mildly anxious & 477 & 604 & $<0.001$ \\
& $(\%)$ & $(71.0)$ & $(88.0)$ \\
Highly anxious & 109 & 78 & 0.01 \\
& $(\%)$ & $(16.2)$ & $(11.4)$ \\
\hline
\end{tabular}

Oversedated $=$ Observer's Assessment of Awareness $/$ Sedation $(\mathrm{OAA} / \mathrm{S}$; reference 4$)$ score of 1 or 2 . Sedated $=\mathrm{OAA} / \mathrm{S}$ score 3 or 4 with no complaints of anxiety; calm or mildly anxious = OAA/S score of 4 or 5 with no or a little anxiety; highly anxious = seriously anxious and/or being regarded to need more anxiolysis. Chi-square test was used to detect differences.

effects like respiratory depression. ${ }^{2}$ Regardless of anesthesiologists' preferences, patients do not always appreciate preoperative sedation and amnesia $^{3}$ that may lead to impersonal treatment or even mistakes. Our study suffers from several limitations, e.g., observers were unblinded and validated psychological questionnaires to measure anxiety were not used. Nonetheless, we feel that the results of this preliminary study suggest that entering the OR on foot contributes to the reduction of preoperative anxiety.

Yuko Kojima MD

Hiroaki Ina MD

Takashi Fujita MD

Hiroyuki Mitono MD

Suwa, Japan

\section{References}

1 Tornetta FJ. A comparison of droperidol, diazepam, and hydroxyzine hydrochloride as premedication. Anesth Analg 1977; 56: 496-500.

2 Moyers JR, Vincent CM. Preoperative medication. In: Barash PG, Cullen BF, Stoeling RK (Eds.). Clinical Anesthesia, $4^{\text {th }}$ ed. Philadelphia: Lippincott Williams \& Wilkins, 2001: 551-65.

3 Korttila K, Aromaa U, Tammisto T. Patient's expectations and acceptance of the effects of the drugs given before anaesthesia: comparison of light and amnesic premedication. Acta Anaesthesiol Scand 1981; 25: 381-6. 
4 Chernik DA, Gillings D, Laine $H$, et al. Validity and reliability of the observer's assessment of alertness/sedation scale: study with intravenous midazolam. J Clin Psychopharmacol 1990; 10: 244-51.

\section{Preventing contamination of propofol infusions}

To the Editor:

Lorenz et al. ${ }^{1}$ examined the bacterial contamination rate of propofol syringes and infusions that were prepared according to: a) the manufacturer's strict guidelines for aseptic handling technique; and b) an alternate method of refilling syringes using what the authors refer to as a closed loop system. While the alternate method may be more efficient and economical, it cannot be properly described as a closed loop system because the stem of the syringe plunger may come into contact with the inside of the syringe during repeated filling. This is a potential source of contamination not associated with single use. Although the authors detected no difference in bacterial contamination rates between the two methods, the sample size of 80 patients is small and we remain concerned that anesthesiologists will endanger patients and assume increased medico-legal risks if they do not follow the manufacturer's recommended procedure.

Thomas Hackmann MD FRCPC

Chris S. Soder MD FRCPC

Halifax, Nova Scotia

\section{Reference}

1 Lorenz IH, Kolbitsch C, Lass-Flörl C, et al. Routine handling of propofol prevents contamination as effectively as does strict adherence to the manufacturer's recommendations. Can J Anesth 2002; 49: 347-52.

\section{REPLY:}

We welcome the comments by Drs. Hackmann and Soder on our article. ${ }^{l}$ We agree that the stem of the syringe plunger may come into contact with the inside of the syringe during repeated filling and that this is a potential source of contamination. We wish to clearly state that the main intention of this study was to subject the manufacturer's as yet unvalidated recommendations to a scientific study of the frequency of contamination of propofol syringes. It was in no way our intention to recommend that propofol be handled in a manner that deviates from the manufacturer's recommendations.
Christian Kolbitsch MD

Innsbruck, Austria

\section{Reference}

1 Lorenz IH, Kolbitsch C, Lass-Florl C, et al. Routine handling of propofol prevents contamination as effectively as does strict adherence to the manufacturer's recommendations. Can J Anesth 2002; 49: 347-52.

\section{Short-and long-term efficacy of oral ketamine in eight chronic-pain patients}

To the Editor:

Ketamine, as a $\mathrm{N}$-methyl-D-aspartate antagonist, has a noticeable analgesic action and can be used for the treatment of neuropathic pain. ${ }^{1-3}$ We studied the effect of oral ketamine in eight chronic neuropathicpain patients.

Patients relieved by the iv infusion of ketamine were entered in the study (Table). After informed consent had been obtained, eight patients were randomly assigned to receive oral ketamine syrup $\left(0.5 \mathrm{mg} \cdot \mathrm{kg}^{-1}\right)$ or the same volume of a placebo syrup every six hours for a week. After seven days the pain was rated by the patient on a visual analogue scale, and allodynia was rated on a four-point verbal rating scale. The plasma concentration of ketamine was measured at five, ten, $30,60,120$, and $180 \mathrm{~min}$ after its administration in all patients on the seventh day. In this short-term study, the severity of the pain and allodynia was reduced by oral ketamine administration about $15 \mathrm{~min}$ after administration, and improvement lasted from six to eight hours. Two of the eight subjects complained of headache relieved by loxoprofen. One patient complained of nightmares reduced by the coadministration of diazepam and of slight dizziness that required no treatment. Ketamine plasma levels were below the limit of detection $\left(0.05 \mu \mathrm{g} \cdot \mathrm{mL}^{-1}\right)$ in all patients despite good pain relief.

In addition, we assessed pain relief and side effects in four of eight patients treated with oral ketamine for more than nine months. We also measured the plasma concentration of ketamine $12 \mathrm{hr}$ after oral administration in two patients. In the long-term study, the severity of pain during daily life was reduced in all four patients (Table). We could reduce the dose of oral ketamine in two patients and of other analgesics in all patients. The plasma concentration of ketamine was $0.46 \mu \mathrm{g} \cdot \mathrm{mL}^{-1}$ in patient one and under the limit of detection in patient four. 